\title{
Chikungunya Outbreak from 1952-2019: A Prospective to Cope-Up with this Re-emerging Disease
}

\author{
Prashant Saxena ${ }^{1,2 *(D)}$, Sanjay Mishra ${ }^{2}$ (D) \\ 1 Department of Biotechnology, KS Vira College of Engineering \& Management Bijnor UP (W) -246701 India \\ 2 School of Biotechnology, IFTM University, Moradabad, UP (W) -244102 India \\ * Correspondence: prashant347@gmail.com;
}

Scopus Author ID 57216215361

Received: 10.10.2020; Revised: 10.12.2020; Accepted: 12.12.2020; Published: 16.12.2020

\begin{abstract}
Chikungunya is a mosquito-borne disease caused by the alphavirus that belongs to the family Togaviridae. It was first identified in 1952 when the first outbreak of chikungunya occurred in the Tanganyika. From them, several outbreaks had been taken place around the globe, making a severe threat to the human population. High-grade fever, nausea, and body pain mislead the disease with Dengue fever. Disease effects are long-lasting; the disease is characterized by severe joint pains, which leads to arthralgia. To date, no direct treatment is available for the infection, which puts a heavy burden on society. In this review article, the authors focus on the outbreaks of chikungunya since1952 to 2019 worldwide. The mutations occurred in the proteome of chikungunya. The evolution occurred because of those mutations and their effects on human societies. The study results that the two mutations in the proteome made the species more vulnerable to society. The outbreak study suggests that numerous chikungunya cases had been identified worldwide with the common symptoms that turn severe with these mutations. This study result reveals that scientists and researchers must focus on the disease's intensity and work progressively to find the solution for this emerging disease.
\end{abstract}

Keywords: chikungunya; CHIKV; outbreak; vaccine.

(C) 2020 by the authors. This article is an open-access article distributed under the terms and conditions of the Creative Commons Attribution (CC BY) license (https://creativecommons.org/licenses/by/4.0/).

\section{Introduction}

Chikungunya caused by the CHIK virus belongs to the Togaviridae family of the genus alphavirus. It is transmitted via mosquitoes [1]. The first presentation was made by the virus in 1952 when a case was found in Tanzania (Previously known as Tanganyika). The first chikungunya outbreak occurred in 1953 in Tanzania. The outbreak affected a large number of population. The vast majority of the population got affected by the infection, and the sickness made an astounding entry into society [2].

The transmission of the CHIKV virus begins with the bite of an infected mosquito called Aedes aegypti or Aedes albopictus. Some cases had been registered in recent days, which was transmitted from pregnant mother to child [3]. Once the virus reaches the host body, it replicates into the skin. It then disperses to the liver and joints through circulating into the bloodstream [4]. The incubation period ranges from 3 to 12 days after that clinical symptom appears.

The chikungunya disease has a resemblance to Dengue. However, extreme joint pain is the differentiating feature of chikungunya make it not as same as dengue [5]. Common symptoms like high-grade fever, rigors, headache, and rashes on the skin [6-7]. The chronic phase of chikungunya is mainly characterized by severe joint pain, which turns to inflammatory 
rheumatism [8]. In some cases, it impacts the patients' mental health, which affects the patient's life [9-10]. In mice, IL-6 and IL-12 (Interleukin) were found circulating at a high level in the chronic CHIKV conditions. IL- 6 is found explicitly in the affected joints and stimulates the expression of apoptosis regulator gene RANKL and suppressed the function of osteoprotegerin, a binding partner of RANKL, released by osteoblasts results in osteoclastogenesis and bone loss [11-12].

Africa is the first continent to face the first-ever case of chikungunya in the year 1952 in Tanzania. After that, several countries of the African continent faces the effect of chikungunya. In 1956 South Africa faced another outbreak of chikungunya and still bearing the burden of disease [13]. Central African Republic, Uganda, Nigeria, and the Democratic Republic of Congo had experienced a progression of outbreaks during the year 1960's to 1990's. Lamu island of Kenya battled with the extraordinary outbreak in 2004 ; over $70 \%$ of the populace got infected by chikungunya [14].

The distribution pattern of the chikungunya virus consists of an epidemic as well as sporadic cases. The capability of disseminating virus become scattered throughout the globe. The distribution of CHIKV into the new graphical areas is mainly caused by viremic people traveling [15].

Chikungunya virus has been distributed in more than 40 countries. Millions of people got affected worldwide, even though indirect methods of treatments are used like antipyretic, and analgesic drugs are used to lower the temperature and pain. The heavy burden of this disease needs supportive therapy and the proper vaccination to treat the disease $[16,14]$.

\section{First Outbreak and Expansion of Disease}

The very first outbreak of chikungunya took place in the year of 1953 in Tanzania. Several country villages experienced the outbreak in which $60 \%-80 \%$ of people from each village got affected within 2-3 weeks. The affected peoples were categorized based on the symptoms; the maximum number of peoples got affected with severe pain and high-grade fever, i.e., $102^{\circ} \mathrm{F}-105^{\circ} \mathrm{F}$. The severity of joint pain causes immobilization in many patients. Some of the affected people experience Hot \& swollen joints. Some patients got affected the second time and experienced joint pain with pyrexia [17]. With this beginning, chikungunya came into knowledge. It then kept on invaliding to various parts of the world, such as Asia, Africa, Europe, America, etc. (Figure 1).

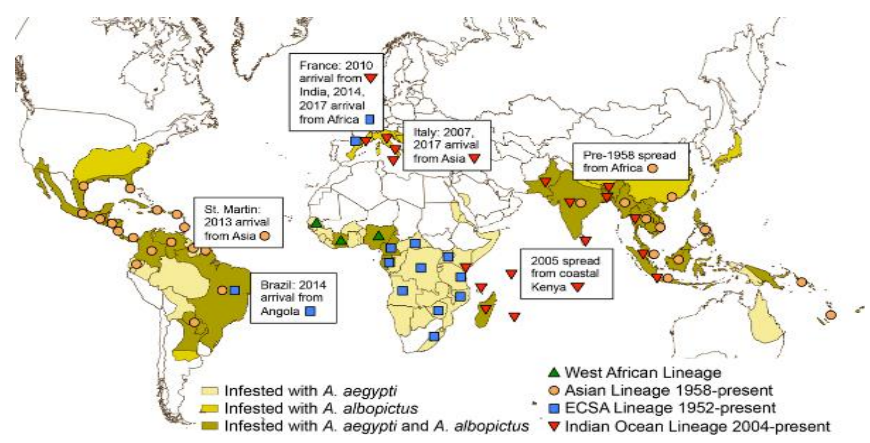

Figure 1. The Global expansion of Chikungunya infection. Different color represents the infections caused by the different vector species, and the symbols represent the genotype of the virus. Reprinted from an open-access source [18].

Mainly the infection was taking place in the two districts, i.e., Newala and Masasi. The main vector of the disease was Aedes aegypti and Culex fatigans [19]. Plateau region, situated 
on a high altitude approximately 2000 feet from the level of the sea, had experienced a similar kind of infection pattern in all the societies. The infection was mostly found in adults $(>45$ years of age) or the infants. Once the infection happened to the family member, all the family members got affected by the disease.

Several cases of febrile illness were registered at Moshi, Tanzania. The PCR (Polymerase Chain Reaction) study revealed that the CHIKV infection is more common than DENV infection. The PCR study results show that among 700 participants, 55(7.9\%) was having CHIKV infection [2]. The result revealed that CHIKV infection is more common in infants or children in comparison with adults.

\subsection{Expansion of CHIKV to Africa.}

After the first outbreak in Tanzania, the second outbreak occurred in Africa's regions in the year 1956. From that point, several incidences had occurred. During 1960-1990 several regions such as Angola, Burundi, Central African Republic, Democratic Republic of Congo, Guinea, Malawi, Nigeria, South Africa, and Uganda of the African continent got affected of registered cases increased drastically. In early 2004, the infection remerges on Lamu Atoll, Kenya, and was distributed in the surrounding regions like La Reunion, Comoros and so on, resulting in roughly about a million cases. The CHIK virus was recognized first time in 2005 with a certain number of cases, while in 2006, the number of enrolled cases expanded dramatically. When the epidemic was reached at its peak, approximately 40,000 cases were getting enrolled every week. Based on the data obtained from the diagnostic labs, it was anticipated that approximately 266,000 cases [20] would get registered during the outbreak. The extraordinary highlights of contamination additionally came into the information. Neurological appearances, fetal contaminations, and mortality [21] were likewise seen during the episode that happened in 2006 [22].

In 2006, more than 400 cases were reported in the Kumbo, northwest part of Cameroon, showing the pattern of dengue-like fever. Among the obtained sample, 105 samples were tested against the DNIV, ONNV, and CHIKV. A total of 54 (51.42\%) samples were detected with the IgM anti-CHIKV, and none of the samples was found positive against the DNIV and ONNV [23]. This concludes that chikungunya causes the outbreak to take place in the region.

In 2010, a contemporaneous outbreak of CHIKV and DENV took place in the Ogooue and Haut Ogooue region. A study revealed that approximately 2731 suspected cases got registered; out of that, $1208(44.23 \%)$ cases were confirmed after the laboratory examination. Laboratory examination revealed that Aedes albopictous was the main vector of the cause [24]. At Mercy Hospital in Bo, Sierra Leone, in the year 2012, among the 932 registered febrile patients, a study was performed by using lateral flow immunoassay [25] to determine the circulating vector of this cause, among 932, 400 (42.91\%) patients were identified positive against the CHIKV infection.

\subsection{Expansion of CHIKV to Europe.}

Italy is the $1^{\text {st }}$ city in Europe, where the first chikungunya outbreak was registered in 2007 [26]. However, some cases of chikungunya may also get registered in Europe. Emilia Romagna region of Ravenna province from North East Italy observes the chikungunya outbreak, where 217 human cases [27] were registered. The laboratory tests confirmed that Aedes albopictus was the source of the infection [13]. The patients were noticed with severe 
back pain, joint pain, febrile illness, and skin rashes. In 2017, Italy experienced a secondary autochthonous outbreak of chikungunya infection; this indigenous was more virulent than the previous one. The number of cases increased, and more than 499 laboratory-confirmed cases of chikungunya infections were identified in the region [28].

In 2009 France encountered the case of CHIKV in a traveler of France who returned from the Maldives. In 2010, the autochthonous transmission of CHIKV caused the chikungunya infection, and 2 cases were identified for the CHIKV positive [29]. Again, in the year 2014, the environmental conditions were found favorable for the autochthonous transmission of CHIKV. This outcome is an aggregate of 126 laboratories affirmed cases of chikungunya on the land of France. The voyager who got back from the Caribbean islands faces the outbreak at the island, and they were the reason for the disease in France [30]. Aside from this, few such events occurred in Europe, where voyagers from various world pieces were the primary driver of the CHIKV contamination. Likewise, Spain and Portugal have met with such events that 10 and 4 instances of CHIKV infection were found, respectively [31].

In the year 2008 to 2011,130 cases of chikungunya and Dengue were identified. Among these $42.8 \%$ (56 cases) of chikungunya were confirmed based on laboratory examinations. The identified CHIKV cases were mainly imported from Mauritius, Maldives, Bali, and Sri Lanka. Special surveillance for the summer fever was arranged in Veneto city (Northeastern part of Italy) to control infectious diseases. From 2010 to 2012, 234 patients were found with high-grade fever and nausea-like symptoms during this surveillance. The laboratory examination revealed that out of 234 registered patients, 24 were found positive for Dengue, and 03 were found positive for the chikungunya [32].

In September 2009, CHIKV infection was reported in 2 travelers of Germany who returned from the Maldives. Apart from that, during the years 2006 to 2009, several chikungunya cases came into focus. However, all the cases belong to the travelers who visited the place where the outcome was going on. The environmental conditions of Germany are not favorable for the vector. However, it is confirmed that the vector is circulating in the region [33]. In Belgium, from 2006 to 2008, 54 cases of chikungunya have been reported. Most of the affected people were reported that they returned from the countries where CHIKV epidemics were prevalent.

\subsection{Expansion of CHIKV to America.}

The United States remained untouched by this severe infection for a long; only 3 cases were registered between 1995 to 2005 . These 3 registered patients were travelers returning from the places where the outbreak took place [15]. From 2006 to 2013, the number of chikungunya cases was increased slightly, i.e., 26 cases per year. However, this number increased to 29 per year later on. All the registered cases were viremic on returning to the US from the region where the disease's risk was high.

The emergence of chikungunya disease in the United States began in 1823 when the Zanzibar identified the chikungunya-like disease. The disease is named based on the symptoms that appeared. The disease was named "Kindinga Pepo" which means disease characterized by sudden cramp-like seizures [34]. The term chikungunya was first introduced in America in late 2013 when acute \& chronic cases were identified; about 1.1 million cases [35] of chikungunya were identified within a year. The registered cases were range from severe cases to death. However, the ratio of deaths was found $<1 \%$ [36]. 
Chikungunya was first reported in Saint Martin and then spread over the 45 countries of North, South, and Central America. Till 2016 more than 2.9 million cases were registered; among that, 296 deaths were confirmed [37]. The infection's risk factor caused by the mosquito-borne diseases was very high in the Dominican Republic region (41\%) and Suriname $(90.4 \%)$. The peak of the transmission of the infection was reached within 3 months.

Since 2016 CHIKV is still circulating in many countries of America and causing the disease. Travel and trade are the best-suited way for CHIKV to spread geographically and become conceivable with favorable virus-vector conditions and environmental factors. The environmental and ecological factor plays an important role in the prognoses of disease. Understanding such factors may help in calculating the risk factor of the infection. Some environmental factors work as a potential indicator to check the CHIKV activity [38].

Brazil, the largest country in South America, encountered the first outbreak of chikungunya in 2014 by the two different genotypes. These two genotypes, Asian/Caribbean genotype and African ECSA genotype, entered Brazil via North region and North-East region respectively and affected Brazil very hardly with this infection [39]. In 2016, the chikungunya outbreak was caused by the same genotypes with high intensity, which confirms the 200 thousand cases of chikungunya in Brazil [40-41].

\subsection{Expansion of CHIKV to Asia.}

In Asia, Bangkok was the primary spot where chikungunya was recognized in 1958; the illness continued extending till 1964 and again reappeared in 1970 and got declined in 1976. The illness's fundamental driver was the Asian genotype of CHIKV, and the vector was Aedes aegypti [42]. The illness reappeared in Southern Thailand in the year 2008-2009, in which around 45000 cases were enlisted. The infection was the ECSA genotype (East Central South African) of CHIKV, and the vector was Aedes aegypti [43]. This time the disease was more virulent due to a mutation in the envelope protein E1 (E1-A226V) [44]. Disease again reemerged in the year 2013 in North East Thailand with the same ECSA genotype. The disease is getting more virulent in the country day by day; the average of registered cases (Laboratory approved) is approximately 179 per year [45]. The country has faced a large burden of the disease because the frequency of the traveler to the country is too high. In 2019 Thailand again faced another chikungunya outbreak. The research study revealed that the main causative vector for this outbreak was Aedes aegypti. According to Thailand's health bulletin, the infection was found in the 27 provinces of Thailand, and 3794 laboratory-confirmed cases were identified [46].

China confronted a significant chikungunya outbreak in the year 2010. In the Guangdong Province of China, individuals were detailing the dengue-like indications; in the laboratory testing, it was seen that the dengue fever did not bring the high-grade fever with the joint agony while CHIKV is the reason for that. The first chikungunya case was accounted for on the first of September. The quantity of cases expanded quickly, which demonstrates a serious episode in the city. The 174 cases were accounted for, and none of the patients had a movement history, which affirms the area's outbreak [47]. The laboratory study confirmed the ECSA genotype of CHIKV, and the vector was Aedes albopictous. In 2017, the Zhejiang province of China encountered the chikungunya infection outbreak; the laboratory testing revealed that it belongs to the ECSA genotype. Like the Indian Ocean region's virus, the virus was imported by the visitors who returned from the regions of Bangladesh [48]. 
Asian country Singapore is endemic to Dengue since 1960. The chikungunya case was unknown until 2006; in 2007, chikungunya's first case came into knowledge, while the first outbreak occurred in 2008. The ministry of health registered 2626 cases from a radius of 150 $\mathrm{m}$ from the region where the $1^{\text {st }}$ case had registered. Aedes aegypti was the vector in the outbreak [49].

Malaysia had experienced various chikungunya outbreaks. The region of this was the same as Thailand, a high traveler index. The first chikungunya was observed in Klang in 1998, followed by an outbreak in 2006 in Perak's rural area. Further, in 2008, the urban area of Johor experienced another chikungunya outbreak. The outbreak in 1998 was caused by the Asian genotype, while the further outbreak was caused by the ECSA genotype [50-51]. The disease had re-emerged in 2009, and a seroprevalence study was performed in the four states (Kuala Lumpur, Negeri Sembilan, Pahang, and Selangor). A total of 945 serum samples were collected, out of which 56 (5.9\%) cases were found positive for the CHIKV infection. The retrospective study that took place during 2006-2009 suggested that among the 13759 identified cases, 6314 (45.88\%) were confirmed based on laboratory diagnosis, while 7445 $(54.11 \%)$ were considered based on the clinical symptoms [50].

Bangladesh had experienced a major outbreak in the country's capital, Dhaka, in 2017 [52]. The disease is prolonged in the region from January to September. This outbreak affects most of the surrounding area. Environmental conditions were suitable for the vector to cause the infection. The outbreak of Bangladesh characterizes the special symptoms. Joint pain is the main characterization of CHIKV infection, which occurs at the onset of infection. However, in Bangladesh's outbreak, joint pain was observed in the patient before the fever [53]. A serological study was performed, in that 1526 total, suspected cases were considered for the laboratory diagnosis. The samples were tested against the IgG and IgM. Among the 1526 samples, 1179 (77.26\%) were found positive for the CHIKV infection. Among the 1179 positive cases, 1103 cases were found positive for $\operatorname{IgM}, 767$ for $\operatorname{IgM}$, while 691 were found positive for $\operatorname{IgG} \& \operatorname{IgM}[54]$.

In late 2016 and early 2017, Pakistan faced a severe outbreak in Karachi. The disease is circulating in the country moderately. The first human cases were identified in the year 2011 when DENV outbreak took place. At the same time, some collected samples were found positive for the CHIKV infection. In 2017, 738 samples were collected for the testing, and 542 were found positive for the CHIKV infection [55]. Viremic exposure and traveler history was the reason for the outbreak. In a short time, the infection spread over the country, and Pakistan's health ministry declared the country's CHIKV outbreak. Another study suggested that the CHIKV infection was circulating in Pakistan since 2015. A cross-sectional study was performed in a certain region in which 997 candidates were chosen; among them, 162 were found positive for the CHIKV infection [56].

Iran, a country of the western Asian region, experienced a chikungunya outbreak in 2017-2018. Genotypic and phenotypic studies revealed that the strain was similar to the Pakistan strain, which caused the chikungunya outbreak in 2017. The identified genotype belongs to the Indian ocean sub-lineage of ECSA genotype [57].

Chikungunya is notable in India since 1963. The whole first episode of chikungunya had occurred in the Eastern piece of the nation and influenced countless the populace. The infection had no history, so it got mistaken for dengue fever. However, laboratory tests affirm that Dengue was not the same and described by joint agony and high-grade fever [58]. In the resulting year 1964, CHIKV caused disease in the area of South India (Vellore, Pondicherry, 
Chennai); 306 cases were distinguished positive for the CHIKV contamination. In 1965 the CHIKV disease enters India's province that is Andhra Pradesh (Now partitioned into two sections Andhra Pradesh and Telangana). The disease's power was high and arrived at different areas of the satiates (Vijayawada, Vishakapattanam, Rajamundry and so on). In 1973, the contamination arrived in North India and was first found in the Barsi (Bhiwani, Haryana). The contamination was brought by the Asian genotype around the nation [59].

The disease disappears after 1973 and again re-emerged after 32 years with the more virulent form and caused a major outbreak in the various states of India, including Tamilnadu, Karnatka, Andhra Pradesh, Maharastra, West Bengal, Uttar Pradesh, \& Madhya Pradesh. The virus's genotype had changed this time; the African genotype was the cause of the infection [59].

The CHIKV infection re-emerged in December 2005 and caused a severe outbreak across the country. Karnataka and Andhra Pradesh were the worst in the condition regarding the infection. Other than that, 17 states of the country were affected due to the infection. According to the NVBDCP 1.39 million cases were registered throughout the country [60]. The main causative agent was Aedes aegypti \& Aedes albopictus. Laboratory testing suggests the availability of the Central East Africa genotype of the virus in the region. The infection hit hardly the coastal regions of South India. The ministry of health, govt of India, had declared the Chikungunya outbreak in the country. The disease was spread progressively in Andhra Pradesh in Feb 2006 while Karnataka in March 2006 [61]. A DALY (Disability-adjusted life years) study was performed to calculate the chikungunya epidemic's total economic burden in 2006. It was found 391 million, out of which only Karnataka state had $55 \%$ of the total burden [62].

In 2007 the infection made a drastic sought in Kerala, India. The positively affected district was Alappuzha, which made an $82.44 \%$ contribution to the infection [63]. , A total of 3.6 million cases of fever, was identified, which was $11.3 \%$ of the total population. The identified vector was Aedes albopictus, and the genotype of the virus was ECSA. The CHIKV was more virulent this time, and it was found due to the mutation in the envelope protein, i.e., E1-A226V. A total of 24052 confirmed chikungunya cases were identified by the Department of Health \& Family Welfare of Kerala district. Kottayam and Pathanamthitta was the second most affected district after the Alappuzha district [64].

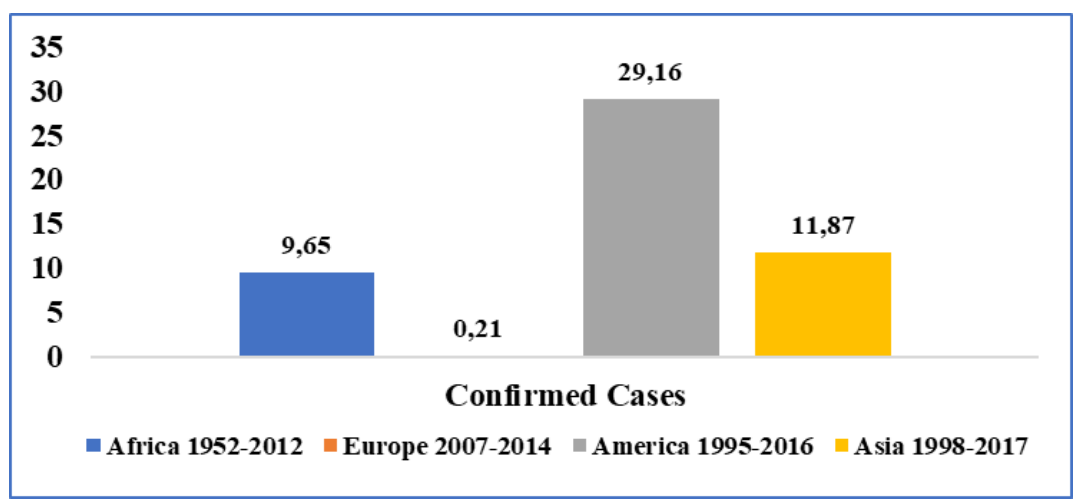

Figure 2. The confirmed cases of Chikungunya infections across the globe. The graph represents the data from the beginning of the infection to the most recent infection identified. (*The data represented in this graph is being collected from the various research papers published globally and contains data only from the cited papers of this manuscript) ( $\mathrm{Y}$-axis data is in Lakhs). 
After 2007 chikungunya started declining in the country till 2016. A massive outbreak of CHIKV infection occurred in the various states of India. The severity of the infection was noted in Delhi and Karnataka. A total of 64057 cases was registered in the country, out of which 26364 were found positive for the chikungunya infection. Karnataka's total contribution $(23.43 \%) \&$ Delhi $(18.75 \%)$ was more than $40 \%$. The outbreak results in a long-lasting effect on the affected people; post-acute phase complications had been observed in the patients [65]. After 2016 various chikungunya cases had been registered across the country according to the various medical reports, newspapers, and NVBDCP. However, the chikungunya outbreak was observed after the country's 2016 Delhi outbreak (Figure 2) [66].

\section{Mutations in the CHIKV}

Chikungunya has various isolated strains. These isolated strains were tested among each other to find out the conserved and variable region of the genome and their consequences on the population. Chikungunya genome has been divided into two regions, i.e., structural protein and non-structural protein. This further segment is subdivided into 6 and 4 regions, respectively. E1 \& E2 region of structural protein had been found with the 8 and 1, point mutation position among the sequences of various strains. E1 (M269V, D284E, P294L, S295F, A316V, V322A, C328W) [67] protein of various strains found the said mutation, and this enhanced the virulence and increased the transmissibility.

In contrast, the E2-K200R [68] enhanced viral dissemination and pathogenicity. The well-known mutation in the E1-A226V increased the Aedes albopictus in comparison to Aedes aegypti [69]. This particular mutation helped the vector in midgut infectivity, disseminate the salivary gland, and transmit the salivary gland. This mutation was the reason for the vast Kerala outbreak in 2007. Only one mutation was found in non-structural protein, i.e., nSP1-R532H; reduced infectivity was observed in the mouse due to this point mutation [70]. The phylogenetic analysis of the strain found in the 2016/2017 chikungunya outbreak revealed that the strain was more similar to the recent Delhi outbreak strain and the Bangladesh strain with some mutations in the E1 region proteome. These changes made species more virulent, and the mutations were predominant in the outbreak of 2017. The identified mutations were K211E, M269V, D284E, $\mathbf{I 3 1 7 V}$, and V322A. The I317V mutations were a novel mutation found only in the Delhi outbreak's strain [71].

\section{Discussion}

The CHIK virus causes chikungunya to belong to the genus alphavirus family Togaviridae [72]. Chikungunya comes into the knowledge after its first outbreak in Tanzania in 1953; after that, several outbreaks had occurred, which had affected many populations around the globe. This disease spread out from the various regions after the first appearance, and it is re-emerged after a long time. The second emergence of the disease was more virulent and long-lasting than the first one [73]. The main reason for the progression of this infection is the misleading symptoms of dengue infection. The infection's typical features are high-grade fever, nausea, headache, joint pain, and arthralgia. Joint pain is the characteristic of the chikungunya infection, while the other features are similar to dengue fever [74]. It affects people from all age groups, from infants to adults; the disease's severity is more in the people belongs to the age group of 16-45 years. Previously it was assumed that chikungunya does not transmit from the pregnant mother to the child. However, in recent days few cases of maternal 
chikungunya had been identified [75]. Chikungunya has chronic symptoms like body rashes, cranial cramps, arthritis, and severe joint pain for a prolonged time.

The disease is mainly caused by the female mosquito of the Togaviridae family. The main vectors are Aedes aegypti and Aedes albopictus. The viral genome has three genotypes, i.e., African genotype, Asian genotype, and ECSA genotype. All these three genotypes were found in the outbreak that took place around the globe. The genotypes became more virulent after point mutation took place in the envelope protein, i.e., E1-A226V. This mutation makes the species more virulent. This had been studied from the outbreak that took place before and after the mutation took place. Along with this mutation, the E1 protein has some other point mutation too (M269V, D284E, P294L, S295F, A316V, V322A, C328W) [66], which makes the species more virulent to the population. Disease had spread worldwide; the hilly regions, cities near lakes, rivers, and ocean are more prone to have the disease due to the environment in such a region is suitable for the vector growth.

Recent studies revealed that chikungunya infection brings a heavy financial burden on society and the government. Data collected in the study from the USA revealed that the total financial burden ranges from \$14.8-\$33.4 million (>1\% of the total GDP) on the government [76]. To date, millions of confirmed cases had been identified throughout the world. However, there is no direct medication available as such. Medical practitioners suggest pain-relieving therapies and medicine lower the temperature, but no medicine or vaccine available to date to cure this deadly disease [18].

\section{Conclusions}

Chikungunya is a re-emerging infection around the globe and becoming a threat to human society. The number of countable cases is increasing exponentially throughout the world. To today's date, there is no direct treatment available to combat this re-emerging disease. So, this research study sums up the accessible outbreaks and the genomic transformation of the genome. This research's main objective was to bring the scientific world's focus towards the need for medication for this infectious disease to overcome human society's burden.

\section{Funding}

This research received no external funding.

\section{Acknowledgments}

The authors are thankful to the Management of IFTM University and KS Vira College of Engineering and Management to provide all the necessary facilities and support to carry out this research work. Besides, the authors are highly grateful to Dr. Madhvi Saxena for support during this manuscript's preparation.

\section{Conflicts of Interest}

The authors declare no conflict of interest. 


\section{References}

1. Fatma, B.; Kumar, R.; Singh, V.A.; Nehul, S.; Sharma, R.; Kesari, P.; Kuhn, R.J.; Tomar, S. Alphavirus capsid protease inhibitors as potential antiviral agents for Chikungunya infection. Antiviral Research 2020, 179, https://doi.org/10.1016/j.antiviral.2020.104808.

2. Hertz, J.T.; Munishi, O.M.; Ooi, E.E.; Howe, S.; Lim, W.Y.; Chow, A.; Morrissey, A.B.; Bartlett, J.A.; Onyango, J.J.; Maro, V.P.; Kinabo, G.D.; Saganda, W.; Gubler, D.J.; Crump, J.A. Chikungunya and Dengue Fever among Hospitalized Febrile Patients in Northern Tanzania. 2012, 86, 171-177, https://doi.org/10.4269/ajtmh.2012.11-0393.

3. Gérardin, P.; Barau, G.; Michault, A.; Bintner, M.; Randrianaivo, H.; Choker, G.; Lenglet, Y.; Touret, Y.; Bouveret, A.; Grivard, P.; Roux, K.L.; Blanc, S.; Schuffenecker, I.; Couderc, T.; Arenzana-Seisdedos, F.; Lecuit, M.; Robillard, P.-Y. Multidisciplinary Prospective Study of Mother-to-Child Chikungunya Virus Infections on the Island of La Réunion. PLOS Medicine 2008, 5, https://doi.org/10.1371/journal.pmed.0050060.

4. Robin, S.; Ramful, D.; Zettor, J.; Benhamou, L.; Jaffar-Bandjee, M.-C.; Rivière, J.-P.; Marichy, J.; Ezzedine, K.; Alessandri, J.-L. Severe bullous skin lesions associated with Chikungunya virus infection in small infants. Eur J Pediatr 2010, 169, 67-72, https://doi.org/10.1007/s00431-009-0986-0.

5. Natrajan, M.S.; Rojas, A.; Waggoner, J.J. Beyond Fever and Pain: Diagnostic Methods for Chikungunya Virus. Journal of Clinical Microbiology 2019, 57, https://doi.org/10.1128/JCM.00350-19.

6. Yazdani, R.; Kaushik, V.V. Chikungunya Fever. Rheumatology (Oxford) 2007, 46, 1214-1215, https://doi.org/10.1093/rheumatology/kem059.

7. Bandyopadhyay, D.; Ghosh, S.K. Mucocutaneous manifestations of Chikungunya fever. Indian Journal of Dermatology 2010, 55, https://doi.org/10.4103/0019-5154.60356.

8. Suhrbier, A. Rheumatic manifestations of chikungunya: emerging concepts and interventions. Nature Reviews Rheumatology 2019, 15, 597-611, https://doi.org/10.1038/s41584-019-0276-9.

9. Paixão, E.S.; Rodrigues, L.C.; Costa, M. da C.N.; Itaparica, M.; Barreto, F.; Gérardin, P.; Teixeira, M.G. Chikungunya chronic disease: a systematic review and meta-analysis. Trans R Soc Trop Med Hyg 2018, 112, 301-316, https://doi.org/10.1093/trstmh/try063.

10. Marimoutou, C.; Ferraro, J.; Javelle, E.; Deparis, X.; Simon, F. Chikungunya infection: self-reported rheumatic morbidity and impaired quality of life persist 6 years later. Clinical Microbiology and Infection 2015, 21, 688-693, https://doi.org/10.1016/j.cmi.2015.02.024.

11. Noret, M.; Herrero, L.; Rulli, N.; Rolph, M.; Smith, P.N.; Li, R.W.; Roques, P.; Gras, G.; Mahalingam, S. Interleukin 6, RANKL, and osteoprotegerin expression by chikungunya virus-infected human osteoblasts. $J$ Infect Dis 2012, 206, 455-457, 457-459, https://doi.org/10.1093/infdis/jis368.

12. Roy, E.; Shi, W.; Duan, B.; Reid, S.P. Chikungunya Virus Infection Impairs the Function of Osteogenic Cells. mSphere 2020, 5, https://doi.org/10.1128/mSphere.00347-20.

13. Pialoux, G.; Gaüzère, B.-A.; Jauréguiberry, S.; Strobel, M. Chikungunya, an epidemic arbovirosis. Lancet Infect Dis 2007, 7, 319-327, https://doi.org/10.1016/S1473-3099(07)70107-X.

14. Renault, P.; Balleydier, E.; D’Ortenzio, E.; Bâville, M.; Filleul, L. Epidemiology of Chikungunya infection on Reunion Island, Mayotte, and neighboring countries. Med Mal Infect 2012, 42, 93-101, https://doi.org/10.1016/j.medmal.2011.12.002.

15. Johansson, M.A.; Powers, A.M.; Pesik, N.; Cohen, N.J.; Staples, J.E. Nowcasting the Spread of Chikungunya Virus in the Americas. PLOS ONE 2014, 9, https://doi.org/10.1371/journal.pone.0104915.

16. Pérez-Pérez, M.-J.; Delang, L.; Ng, L.F.P.; Priego, E.-M. Chikungunya virus drug discovery: still a long way to go? Expert Opinion on Drug Discovery 2019, 14, 855-866, https://doi.org/10.1080/17460441.2019.1629413.

17. Robinson, M.C. An epidemic of virus disease in Southern Province, Tanganyika territory, in 1952-1953. I. Clinical Features. Trans $R$ Soc Trop Med Hyg 1955, 49, 28-32.

18. Rezza, G.; Weaver, S.C. Chikungunya as a paradigm for emerging viral diseases: Evaluating disease impact and hurdles to vaccine development. PLoS Negl Trop Dis 2019, 13, https://doi.org/10.1371/journal.pntd.0006919.

19. Lumsden, W.H. An epidemic of virus disease in Southern Province, Tanganyika Territory, in 1952-53. II. General description and epidemiology. Trans $R$ Soc Trop Med Hyg 1955, 49, 33-57, https://doi.org/10.1016/0035-9203(55)90081-x.

20. Borgherini, G.; Poubeau, P.; Staikowsky, F.; Lory, M.; Le Moullec, N.; Becquart, J.P.; Wengling, C.; Michault, A.; Paganin, F. Outbreak of chikungunya on Reunion Island: early clinical and laboratory features in 157 adult patients. Clin Infect Dis 2007, 44, 1401-1407, doi:10.1086/517537.

21. Ramful, D.; Carbonnier, M.; Pasquet, M.; Bouhmani, B.; Ghazouani, J.; Noormahomed, T.; Beullier, G.; Attali, T.; Samperiz, S.; Fourmaintraux, A.; Alessandri, J.-L. Mother-to-Child Transmission of Chikungunya Virus Infection. The Pediatric Infectious Disease Journal 2007, 26, 811-815..

22. Sergon, K.; Njuguna, C.; Kalani, R.; Ofula, V.; Onyango, C.; Konongoi, L.S.; Bedno, S.; Burke, H.; Dumilla, A.M.; Konde, J.; Njenga, M.K.; Sang, R.; Breiman, R.F. Seroprevalence of Chikungunya virus (CHIKV) 
infection on Lamu Island, Kenya, October 2004. The American journal of tropical medicine and hygiene 2008, 78, 333-337.

23. Pistone, T.; Ezzedine, K.; Boisvert, M.; Receveur, M.-C.; Schuffenecker, I.; Zeller, H.; Lafon, M.-E.; Fleury, H.; Malvy, D. Cluster of chikungunya virus infection in travelers returning from Senegal, 2006. J Travel Med 2009, 16, 286-288.

24. Demanou, M.; Antonio-Nkondjio, C.; Ngapana, E.; Rousset, D.; Paupy, C.; Manuguerra, J.-C.; Zeller, H. Chikungunya outbreak in a rural area of Western Cameroon in 2006: A retrospective serological and entomological survey. BMC Research Notes 2010, 3, 128, https://doi.org/10.1186/1756-0500-3-128.

25. Ansumana, R.; Jacobsen, K.H.; Leski, T.A.; Covington, A.L.; Bangura, U.; Hodges, M.H.; Lin, B.; Bockarie, A.S.; Lamin, J.M.; Bockarie, M.J.; Stenger, D.A. Reemergence of chikungunya virus in Bo, Sierra Leone. Emerg Infect Dis 2013, 19, 1108-1110, https://doi.org/10.3201/eid1907.121563.

26. Tilston, N.; Skelly, C.; Weinstein, P. Pan-European Chikungunya surveillance: designing risk stratified surveillance zones. International Journal of Health Geographics 2009, 8, https://doi.org/10.1186/1476072X-8-61.

27. Liumbruno, G.M.; Calteri, D.; Petropulacos, K.; Mattivi, A.; Po, C.; Macini, P.; Tomasini, I.; Zucchelli, P.; Silvestri, A.R.; Sambri, V.; Pupella, S.; Catalano, L.; Piccinini, V.; Calizzani, G.; Grazzini, G. The Chikungunya epidemic in Italy and its repercussion on the blood system. Blood Transfusion 2008, https://doi.org/10.2450/2008.0016-08.

28. Riccardo, F.; Venturi, G.; Di Luca, M.; Manso, M.; Severini, F.; Andrianou, X.; Fortuna, C.; Remoli, M.E.; Benedetti, E.; Caporali, M.G.; Fratto, F.; Mignuoli, A.; Rizzo, L.; Vito, G.; Giorgio, V.; Surace, L.; Vairo, F.; Angelini, P.; Re, M.; Rizzo, C. Secondary Autochthonous Outbreak of Chikungunya, Southern Italy, 2017. Emerg Infect Dis 2019, 25, 2093-2095, https://doi.org/10.3201/eid2511.180949.

29. Paty, M.C.; Six, C.; Charlet, F.; Heuzé, G.; Cochet, A.; Wiegandt, A.; Chappert, J.L.; Dejour-Salamanca, D.; Guinard , A.; Soler, P.; Servas, V.; Vivier-Darrigol, M.; Ledrans, M.; Debruyne, M.; Schaal, O.; Jeannin, C.; Helynck, B.; Leparc-Goffart, I.; Coignard, B. Large number of imported chikungunya cases in mainland France, 2014: a challenge for surveillance and response. 2014, 19, https://doi.org/10.2807/15607917.es2014.19.28.20856.

30. Sane, J.; Kurkela, S.; Vapalahti, O. Chikungunya, a new global epidemic? Duodecim 2011, 127, 457-463.

31. Pfeffer, M.; Hanus, I.; Löscher, T.; Homeier, T.; Dobler, G. Chikungunya fever in two German tourists returning from the Maldives, September, 2009. Euro Surveill 2010, 15.

32. Queyriaux, B.; Armengaud, A.; Jeannin, C.; Couturier, E.; Peloux-Petiot, F. Chikungunya in Europe. The Lancet 2008, 371, 723-724, https://doi.org/10.1016/S0140-6736(08)60337-2.

33. Frank, C.; Schöneberg, I.; Stark, K. Trends in imported chikungunya virus infections in Germany, 20062009. Vector Borne Zoonotic Dis 2011, 11, 631-636, https://doi.org/10.1089/vbz.2010.0269.

34. Halstead, S.B. Reappearance of chikungunya, formerly called Dengue, in the Americas. Emerg Infect Dis 2015, 21, 557-561, https://doi.org/10.3201/eid2104.141723.

35. Yactayo, S.; Staples, J.E.; Millot, V.; Cibrelus, L.; Ramon-Pardo, P. Epidemiology of Chikungunya in the Americas. J Infect Dis. 2016, 214, S441-S445.

36. Cardona-Ospina, J.A.; Henao-SanMartin, V.; Paniz-Mondolfi, A.E.; Rodríguez-Morales, A.J. Mortality and fatality due to Chikungunya virus infection in Colombia. $J$ Clin Virol 2015, 70, 14-15, https://doi.org/10.1016/j.jcv.2015.07.001.

37. Pimentel, R.; Skewes-Ramm, R.; Moya, J. Chikungunya in the Dominican Republic: lessons learned in the first six months. Rev Panam Salud Publica 2014, 36, 336-341.

38. Kuno, G. A Re-Examination of the History of Etiologic Confusion between Dengue and Chikungunya. PLoS Negl Trop Dis 2015, 9, https://doi.org/10.1371/journal.pntd.0004101.

39. Naveca, F.G.; Claro, I.; Giovanetti, M.; de Jesus, J.G.; Xavier, J.; Iani, F.C.d.M.; do Nascimento, V.A.; de Souza, V.C.; Silveira, P.P.; Lourenço, J.; Santillana, M.; Kraemer, M.U.G.; Quick, J.; Hill, S.C.; Thézé, J.; Carvalho, R.D.d.O.; Azevedo, V.; Salles, F.C.d.S.; Nunes, M.R.T.; Lemos, P.d.S.; Candido, D.d.S.; Pereira, G.d.C.; Oliveira, M.A.A.; Meneses, C.A.R.; Maito, R.M.; Cunha, C.R.S.B.; Campos, D.P.d.S.; Castilho, M.d.C.; Siqueira, T.C.d.S.; Terra, T.M.; Albuquerque, C.F.C.d.; Cruz, L.N.d.; Abreu, A.L.d.; Martins, D.V.; Simoes, D.S.d.M.V.; Aguiar, R.S.d.; Luz, S.L.B.; Loman, N.; Pybus, O.G.; Sabino, E.C.; Okumoto, O.; Alcantara, L.C.J.; Faria, N.R. Genomic, epidemiological and digital surveillance of Chikungunya virus in the Brazilian Amazon. PLOS Neglected Tropical Diseases 2019, 13, https://doi.org/10.1371/journal.pntd.0007065.

40. Machado, L.C.; Morais-Sobral, M.C. de; Campos, T. de L.; Pereira, M.R.; Albuquerque, M. de F.P.M. de; Gilbert, C.; Franca, R.F.O.; Wallau, G.L. Genome sequencing reveals coinfection by multiple chikungunya virus genotypes in a recent outbreak in Brazil. PLOS Neglected Tropical Diseases 2019, 13, https://doi.org/10.1371/journal.pntd.0007332.

41. Bozza, F.; Moreira-Soto, A.; Rockstroh, A.; Fischer, C.; Nascimento, A.; Calheiros, A.; Drosten, C.; Bozza, P.; Souza, T.; Ulbert, S.; Drexler, J. Differential Shedding and Antibody Kinetics of Zika and Chikungunya Viruses, Brazil. Emerg Infect Dis 2019, 25, 311-315, https://doi.org/10.3201/eid2502.180166. 
42. Fischer, M.; Staples, J.E. Arboviral Diseases Branch, National Center for Emerging and Zoonotic Infectious Diseases, CDC Notes from the field: chikungunya virus spreads in the Americas - Caribbean and South America, 2013-2014. MMWR Morb Mortal Wkly Rep 2014, 63, 500-501.

43. Hammon, W.M.; Rudnick, A.; Sather, G.E. Viruses associated with epidemic hemorrhagic fevers of the Philippines and Thailand. Science 1960, 131, 1102-1103, https://doi.org/10.1126/science.131.3407.1102.

44. Tsetsarkin, K.A.; Vanlandingham, D.L.; McGee, C.E.; Higgs, S. A Single Mutation in Chikungunya Virus Affects Vector Specificity and Epidemic Potential. PLOS Pathogens 2007, 3, https://doi.org/10.1371/journal.ppat.0030201.

45. Le, B.C.T.; Ekalaksananan, T.; Thaewnongiew, K.; Phanthanawiboon, S.; Aromseree, S.; Phanitchat, T.; Chuerduangphui, J.; Suwannatrai, A.T.; Alexander, N.; Overgaard, H.J.; Bangs, M.J.; Pientong, C. Interepidemic Detection of Chikungunya Virus Infection and Transmission in Northeastern Thailand. The American Journal of Tropical Medicine and Hygiene 2020, 103, 1660-1669, https://doi.org/10.4269/ajtmh.20-0293.

46. Intayot, P.; Phumee, A.; Boonserm, R.; Sor-suwan, S.; Buathong, R.; Wacharapluesadee, S.; Brownell, N.; Poovorawan, Y.; Siriyasatien, P. Genetic Characterization of Chikungunya Virus in Field-Caught Aedes aegypti Mosquitoes Collected during the Recent Outbreaks in 2019, Thailand. Pathogens 2019, 8, https://doi.org/10.3390/pathogens8030121.

47. Wu, D.; Wu, J.; Zhang, Q.; Zhong, H.; ke, C.; Deng, X.; Guan, D.; Li, H.; Zhang, Y.; Zhou, H.; He, J.; Li, L.; Yang, X. Chikungunya Outbreak in Guangdong Province, China, 2010. Emerg Infect Dis 2012, 18, 493495, https://doi.org/10.3201/eid1803.110034.

48. Pan, J.; Fang, C.; Yan, J.; Yan, H.; Zhan, B.; Sun, Y.; Liu, Y.; Mao, H.; Cao, G.; Lv, L.; Zhang, Y.; Chen, E. Chikungunya Fever Outbreak, Zhejiang Province, China, 2017. Emerg Infect Dis 2019, 25, 1589-1591, https://doi.org/10.3201/eid2508.181212.

49. Leo, Y.S.; Chow, A.L.P.; Tan, L.K.; Lye, D.C.; Lin, L.; Ng, L.C. Chikungunya Outbreak, Singapore, 2008. Emerg. Infect. Dis. 2009, 15, 836-837, https://doi.org/10.3201/eid1505.081390.

50. Noridah, O.; Paranthaman, V.; Nayar, S.K.; Masliza, M.; Ranjit, K.; Norizah, I.; Chem, Y.K.; Mustafa, B.; Kumarasamy, V.; Chua, K.B. Outbreak of chikungunya due to virus of Central/East African genotype in Malaysia. Med J Malaysia 2007, 62, 323-328.

51. Chua, K.B. Epidemiology of chikungunya in Malaysia: 2006-2009. Med J Malaysia 2010, 65, $277-282$.

52. Rahman, M.; Yamagishi, J.; Rahim, R.; Hasan, A.; Sobhan, A. East/Central/South African Genotype in a Chikungunya Outbreak, Dhaka, Bangladesh, 2017. Emerg Infect Dis 2019, 25, 370-372, https://doi.org/10.3201/eid2502.180188.

53. Hossain, M.S.; Hasan, M.M.; Islam, M.S.; Islam, S.; Mozaffor, M.; Khan, M.A.S.; Ahmed, N.; Akhtar, W.; Chowdhury, S.; Arafat, S.M.Y.; Khaleque, M.A.; Khan, Z.J.; Dipta, T.F.; Asna, S.M.Z.H.; Hossain, M.A.; Aziz, K.M.S.; Mosabbir, A.A.; Raheem, E. Chikungunya outbreak (2017) in Bangladesh: Clinical profile, economic impact and quality of life during the acute phase of the disease. PLOS Neglected Tropical Diseases 2018, 12, https://doi.org/10.1371/journal.pntd.0006561.

54. Rashid, M.D.H.O.; Patwary, M.H.; Imtiaz, A.; Abdullah, S.A.; Zahedur, R.; Ibrahim, K.; Zzaman. M.T. Seroprevalence of Chikungunya during Outbreak in Dhaka, Bangladesh in 2017. J Virol Antivir Res 2018, 07, https://doi.org/10.4172/2324-8955.1000184.

55. Badar, N.; Salman, M.; Ansari, J.; Aamir, U.; Alam, M.M.; Arshad, Y.; Mushtaq, N.; Ikram, A.; Qazi, J. Emergence of Chikungunya Virus, Pakistan, 2016-2017. Emerg. Infect. Dis. 2020, 26, 307-310, https://doi.org/10.3201/eid2602.171636.

56. Barr, K.L.; Khan, E.; Farooqi, J.Q.; Imtiaz, K.; Prakoso, D.; Malik, F.; Lednicky, J.A.; Long, M.T. Evidence of Chikungunya Virus Disease in Pakistan Since 2015 With Patients Demonstrating Involvement of the Central Nervous System. Front. Public Health 2018, 6, 186, https://doi.org/10.3389/fpubh.2018.00186.

57. Pouriayevali, M.H.; Rezaei, F.; Jalali, T.; Baniasadi, V.; Fazlalipour, M.; Mostafavi, E.; Khakifirouz, S.; Mohammadi, T.; Fereydooni, Z.; Tavakoli, M.; Azad-Manjiri, S.; Hosseini, M.; Ghalejoogh, M.; Gouya, M.M.; Failloux, A.-B.; Salehi-Vaziri, M. Imported cases of Chikungunya virus in Iran. BMC Infect Dis 2019, 19, 1004, https://doi.org/10.1186/s12879-019-4637-4.

58. Shah, K.V.; Gibbs, C.J.; Banerjee, G. Virological Investigation Of The Epidemic Of Haemorrhagic Fever In Calcutta: Isolation Of Three Strains Of Chikungunya Virus. Indian J Med Res 1964, 52, 676-683.

59. Yergolkar, P.; Tandale, B.; Arankalle, V.; Sathe, P.S.; Gandhe, S.; Gokhle, M.; Jacob, G.; Hundekar, S.; Mishra, A. Chikungunya Outbreaks Caused by African Genotype, India. Emerging Infectious Diseases journal 2006, 12, https://doi.org/10.3201/eid1210.060529.

60. Lahariya, C.; Pradhan, S.K. Emergence of chikungunya virus in Indian subcontinent after 32 years: A review. J Vector Borne Dis 2006, 43, 151-160.

61. Kaur, P.; Ponniah, M.; Murhekar, M.V.; Ramachandran, V.; Ramachandran, R.; Raju, H.K.; Perumal, V.; Mishra, A.C.; Gupte, M.D. Chikungunya Outbreak, South India, 2006. Emerg. Infect. Dis. 2008, 14, 16231625, https://doi.org/10.3201/eid1410.070569.

62. Krishnamoorthy, K.; Harichandrakumar, K.T.; Krishna Kumari, A.; Das, L.K. . J Vector Borne Dis 2009 , 46, 26-35. 
63. Kumar, N.P.; Joseph, R.; Kamaraj, T.; Jambulingam, P. A226V mutation in virus during the 2007 chikungunya outbreak in Kerala, India. Journal of General Virology 2008, 89, 1945-1948, https://doi.org/10.1099/vir.0.83628-0.

64. Kumar, N.P.; Suresh, A.; Vanamail, P.; Sabesan, S.; Krishnamoorthy, K.G.; Mathew, J.; Jose, V.T.; Jambulingam, P. Chikungunya virus outbreak in Kerala, India, 2007: a seroprevalence study. Mem. Inst. Oswaldo Cruz 2011, 106, 912-916, https://doi.org/10.1590/S0074-02762011000800003.

65. Kaur, N.; Jain, J.; Kumar, A.; Narang, M.; Zakaria, M.K.; Marcello, A.; Kumar, D.; Gaind, R.; Sunil, S. Chikungunya outbreak in Delhi, India, 2016: report on coinfection status and comorbid conditions in patients. New Microbes and New Infections 2017, 20, 39-42, https://doi.org/10.1016/j.nmni.2017.07.007.

66. Jain, J.; Kaur, N.; Haller, S.L.; Kumar, A.; Rossi, S.L.; Narayanan, V.; Kumar, D.; Gaind, R.; Weaver, S.C.; Auguste, A.J.; Sunil, S. Chikungunya Outbreaks in India: A Prospective Study Comparing Neutralization and Sequelae during Two Outbreaks in 2010 and 2016. The American Journal of Tropical Medicine and Hygiene 2020, 102, 857-868, https://doi.org/10.4269/ajtmh.19-0481.

67. Singh, R.K.; Tiwari, S.; Mishra, V.K.; Tiwari, R.; Dhole, T.N. Molecular epidemiology of Chikungunya virus: Mutation in E1 gene region. Journal of Virological Methods 2012, 185, 213-220, https://doi.org/10.1016/j.jviromet.2012.07.001.

68. Hawman, D.W.; Carpentier, K.S.; Fox, J.M.; May, N.A.; Sanders, W.; Montgomery, S.A.; Moorman, N.J.; Diamond, M.S.; Morrison, T.E. Mutations in the E2 Glycoprotein and the 3' Untranslated Region Enhance Chikungunya Virus Virulence in Mice. J Virol 2017, 91, e00816-17, https://doi.org/10.1128/JVI.00816-17.

69. Deeba, F.; Haider, M.S.H.; Ahmed, A.; Tazeen, A.; Faizan, M.I.; Salam, N.; Hussain, T.; Alamery, S.F.; Parveen, S. Global transmission and evolutionary dynamics of the Chikungunya virus. Epidemiology \& Infection 2020, 148, https://doi.org/10.1017/S0950268820000497.

70. Gao, Y.; Goonawardane, N.; Ward, J.; Tuplin, A.; Harris, M. Multiple roles of the non-structural protein 3 (nsP3) alphavirus unique domain (AUD) during Chikungunya virus genome replication and transcription. PLoS Pathog 2019, 15, e1007239, https://doi.org/10.1371/journal.ppat.1007239.

71. Agarwal, A.; Gupta, S.; Yadav, A.K.; Nema, R.K.; Ansari, K.; Biswas, D. Molecular and phylogenetic analysis of Chikungunya virus in Central India during 2016 and 2017 outbreaks reveal high similarity with recent New Delhi and Bangladesh strains. Infection, Genetics and Evolution 2019, 75, https://doi.org/10.1016/j.meegid.2019.103940.

72. Ganesan, V.; Duan, B.; Reid, S. Chikungunya Virus: Pathophysiology, Mechanism, and Modeling. Viruses 2017, 9, https://doi.org/10.3390/v9120368.

73. DeFilippis, V.R. Chikungunya Virus Vaccines: Platforms, Progress, and Challenges. In: Current Topics in Microbiology and Immunology. Springer Berlin Heidelberg: Berlin, Heidelberg, 2019; https://doi.org/10.1007/82_2019_175.

74. Angelini, P.; Macini, P.; Finarelli, A.C.; Pol, C.; Venturelli, C.; Bellini, R.; Dottori, M. Chikungunya epidemic outbreak in Emilia-Romagna (Italy) during summer 2007. Parassitologia 2008, 50, 97-98.

75. Contopoulos-Ioannidis, D.; Newman-Lindsay, S.; Chow, C.; LaBeaud, A.D. Mother-to-child transmission of Chikungunya virus: A systematic review and meta-analysis. PLoS Negl Trop Dis 2018, 12, https://doi.org/10.1371/journal.pntd.0006510.

76. Feldstein, L.R.; Ellis, E.M.; Rowhani-Rahbar, A.; Hennessey, M.J.; Staples, J.E.; Halloran, M.E.; Weaver, M.R. Estimating the cost of illness and burden of disease associated with the 2014-2015 chikungunya outbreak in the U.S. Virgin Islands. PLOS Neglected Tropical Diseases 2019, 13, https://doi.org/10.1371/journal.pntd.0007563. 